\title{
Catamenially Recurring Pneumothorax with Partial Liver Herniation: A Particular View
}

\author{
S. Sanna ${ }^{a} \quad$ M. Taurchini ${ }^{a} \quad$ M. Monteverde ${ }^{a} \quad$ V. Agnoletti $^{\mathrm{a}} \quad$ G.L. Casoni ${ }^{\mathrm{b}}$ \\ aThoracic Surgery Unit and ' Pneumology Unit, 'G.B. Morgagni' Hospital, Forlì, Italy
}

\section{Key Words}

Catamenial pneumothorax • Diaphragmatic hernia

Thoracic surgery $\cdot \mathrm{CT} / \mathrm{MRI}$ scan $\cdot$ Videothoracoscopy

\begin{abstract}
Few cases of catamenial pneumothorax with complete or partial diaphragmatic hernias are reported in the literature. We present herein the case of a 38-year-old woman affected by recurrent right-sided spontaneous pneumothorax during menstrual periods. CT scan revealed normal lung parenchyma and multiple diaphragmatic nodes suspected for endometrial implants. The patient underwent right thoracoscopy and the presence of multiple diaphragmatic perforations of the tendinous part was observed as well as partial hepatic hernia. Through a video-assisted procedure, pleural biopsies and diaphragmatic plication containing the tendinous part with total pleural abrasion and talc pleurodesis were performed. No endometrial implants were found on histologic examination of pleural biopsies. The surgical procedure was uneventful and totally successful. On the basis of the clinical data and endoscopic view, we consider our case as catamenially recurring pneumothorax.
\end{abstract}

Copyright $\odot 2011$ S. Karger AG, Basel
(C) 2011 S. Karger AG, Basel

0025-7931/11/0825-0476\$38.00/0

Fax +4161306 1234

E-Mail karger@karger.ch

www.karger.com
Accessible online at: www.karger.com/res
A 38-year-old woman came to our institution with a recurrent episode of right spontaneous pneumothorax, which had previously been treated with pleural drainage at another hospital. Every episode was claimed to have occurred during menstrual periods. CT scan, completed with multiplanar reformatting (fig. 1a, b), revealed normal lung parenchyma and multiple diaphragmatic nodes on the right side, suspected for endometrial implants. A right videothoracoscopy showed multiple perforations of the tendinous part of the diaphragm, and partial liver herniation was observed as well (fig. 2). Through a videoassisted procedure, we performed pleural biopsies, diaphragmatic plication of the tendinous part, total pleural abrasion and talc pleurodesis. The postoperative period was uneventful. Over 4 months of follow-up, no recurrence was observed.

Catamenial pneumothorax is a rare spontaneous recurring pneumothorax that almost always affects the right side and whose pathogenesis is controversial. The two main hypotheses are (1) migration of air from the peritoneal cavity through pre-existing diaphragmatic defects [1] or (2) transperitoneal, lymphatic-hematogenous endometrial spreading on lung and pleura with tissue rupture and development of pneumothorax in menses [2]. During the diagnostic videothoracoscopic procedure, the pleural cavity should be explored for en- 

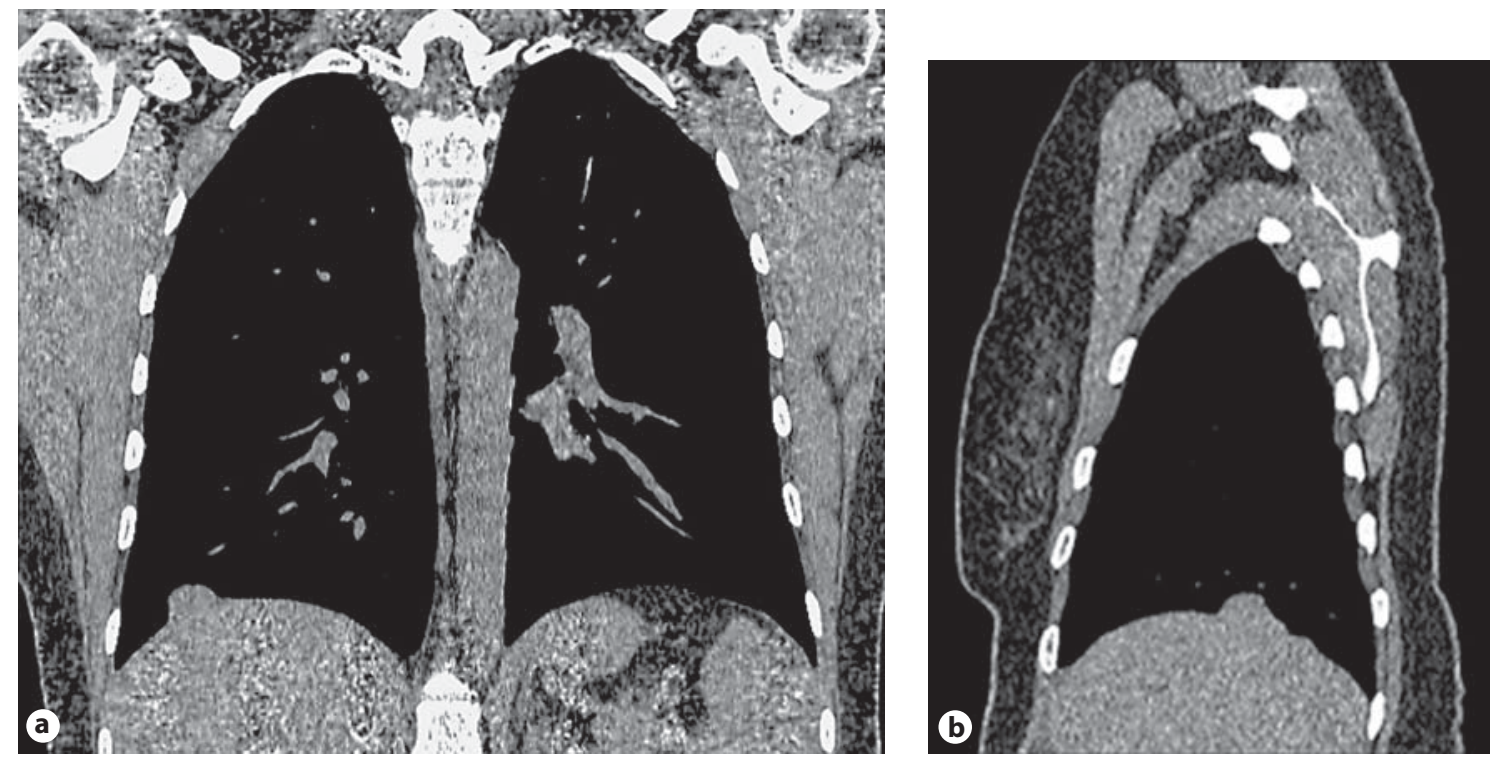

Fig. 1. CT reconstruction, posteroanterior (a) and lateral (b) view, confirming the presence of diaphragmatic 'tumors' suspected for liver herniation or diaphragmatic endometriosis implants.

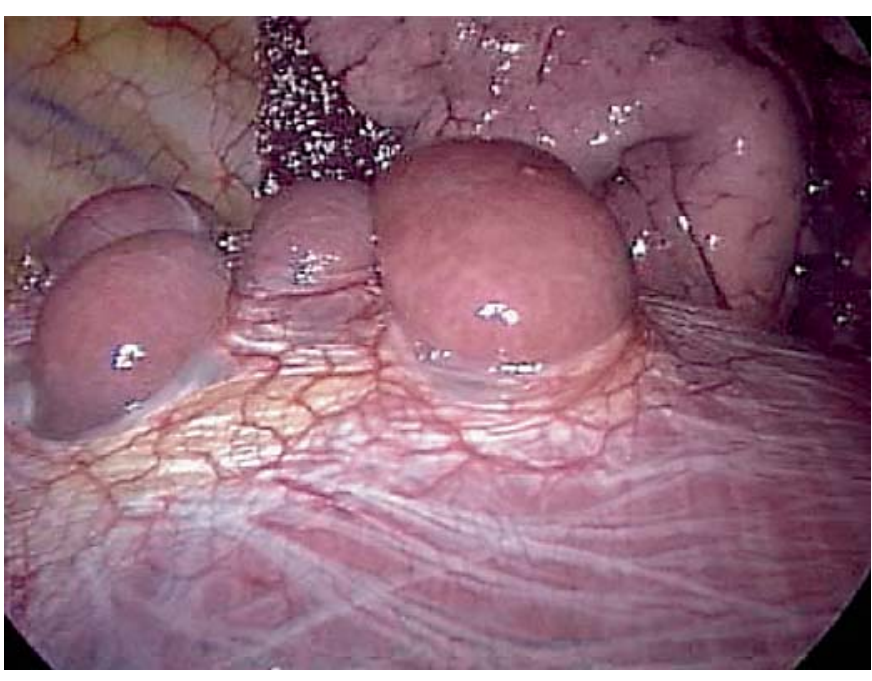

Fig. 2. Video thoracoscopic view of the diaphragm with multiple perforations of its tendinous part with partial liver herniation.

dometrial implants and the diaphragm for multiple perforations, especially in its tendinous part with liver herniation [3], as in our case. The gold standard treatment is hormonal therapy ( $\mathrm{GnRH}$ agonist) to treat endometrial implants [2] and video-assisted surgical plication of the diaphragm with mechanical or chemical pleurodesis $[1,3]$.
On the basis of the clinical data and endoscopic view, although without histologic confirmation of pleural endometriosis, we consider our case as catamenially recurring spontaneous pneumothorax.

\footnotetext{
References

1 Rakotovao HJL, Razafimanjato NNM, Razafindramboa WR, Ratovohery AN, Raoelison TM, Rakotozafy G, Rapelanoro RF, Rajaonarivelo P: Right-sided recurring catamenial pneumothorax complicated by diaphragmatic hernia. Revue Tropicale de Chirurgie 2007;1:48-49.

-2 Augulea A, Lambrinoudaki I, Christodoulakos G: Thoracic endometriosis syndrome. Respiration 2008;75:113-119.

- 3 Ciriaco P, Negri G, Libretti L, Carretta A, Melloni G, Casiraghi M, Bandiera A, Zannini P: Surgical treatment of catamenial pneumothorax: a single centre experience. Interact Cardiovasc Thorac Surg 2009;8: 349-352.
} 